\title{
Information visualization for the taking of decisions
}

\author{
S. Larreina, S. Hernando \& D. Grisaleña \\ Knowledge Technologies Department, Fundación LEIA CDT, Spain
}

\begin{abstract}
Vast amounts of useful information are accessible to us in multiple formats: from structured information in databases to organized documents. However, nobody is able to read this enormous quantity of information since we do not have enough time to do it.

Computer hardware and software developments have encouraged the analysis of great amounts of information and they have also supported real-time, dynamic, interactive and visual representations.

So we prefer graphs, charts, and maps to interpret this information and make decisions.

Data Mining, Text Mining or Web Mining techniques would not be very useful for taking a decision if we could not take advantage from the graphs. The main advantage of these graphical presentations is that we could visualize a great amount of data in a very small amount of space and by using little time. The user can more rapidly explore the information.

There is a strong relationship between the Mining and the information visualization. There is a need for collecting together the results to date, organizing them, understanding the essence of this field and providing materials for the scientific community.

The purpose of this paper is clear: to help the structure of the field, and to suggest possible applications. We will explore some aspects as to how space is used in information visualization or how document collections can be transformed and visualized. We will point out how Data Mining results could serve Business Intelligence applications or Foresight techniques by the creation of scenarios.
\end{abstract}

Keywords: information visualization, Business Intelligence, Foresight, scenario, representation, data analysis, decision making. 


\section{Introduction}

With the flood of data produced by today's information systems, something must be done to allow business decision-makers to extract the information it contains. It is expected that visualization techniques could allow the business decisionmaker to separate the "wheat from the chaff."

Computational intelligence methods such as data mining, "expert" mining (extracting patterns by interacting with experts), machine learning, inductive reasoning strategies, expert systems, fuzzy logic and neural networks help to discover hidden patterns.

It is the collected or generated data, especially their presentations to users in a comprehensible form, that affect and limit the basic capabilities of computing. It is extremely necessary to improve the communication between users and computers, to transform the vast computing-related data into some representations that help humans to understand the data. Humans are visual creatures. Most of what we learn comes through our sight. An effective solution to the challenge is to shift some of the user's cognitive load to human perceptual systems by using computer-generated, domain-specific visualizations.

The paper addresses problems of decision support by discovering and visualizing patterns in a comprehensible form based on structural information analysis.

To achieve this goal, we describe why visualization technology may be appropriate for business problem solving, and some applications of visualization technology.

\section{Mountains of information}

Every day, government, industry, and other institutions create mountains of data, research, and analysis. And every day -driven by very fast advances in computer and communications technology- the information creation rate accelerates.

How can we ensure that people can deal effectively with the mountains of information they'll be facing -and not be buried beneath them?

No matter what kind of information we should retrieve for our projects or activities: economic data, websites, articles or patents. The problem is always the same: 'tons' of information are waiting for our retrieval, analysis, visualization and a subsequent decision.

\section{Too much information, too little time}

The information overload crisis has two core causes. The first is that information technology (IT) has unleashed a vast potential to create and publish huge quantities of content (Tegarden [9]).

The second cause is the limitation of the human brain to be able to make use of all this information. 


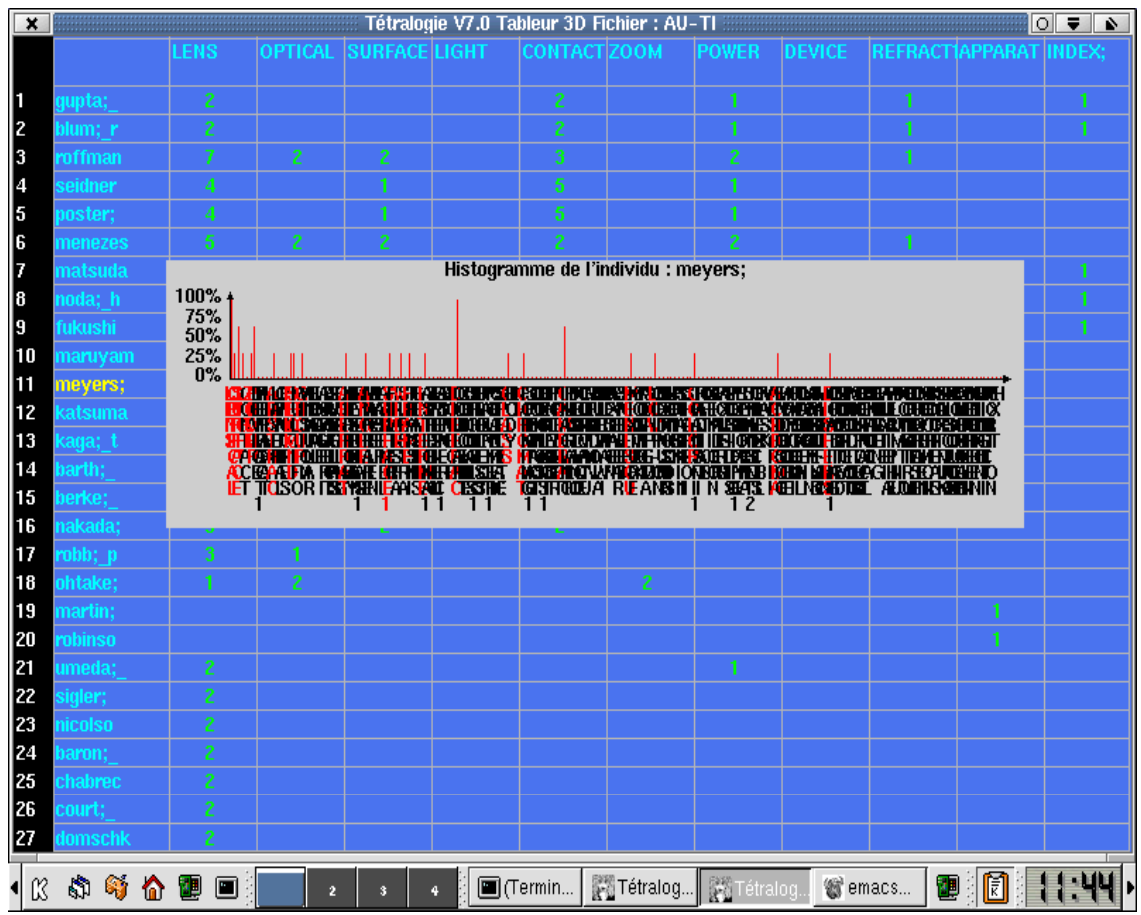

Figure 1: Tetralogie. More than 2 million of concepts are presented within an enormous array. The histogram shows how the inventors relate with the concepts: no way to discover anything.

All of us have ever felt a sense of panic as we realized that we simply didn't have the time or energy to know all you need to know. Emails and mobile phones have speeded up communication, but they have not helped us make better decisions.

IT is supposed to make us more efficient. It's making us more inefficient. It's not more information we need but rather more time, more analysis, more judgment.

\section{The solution: information visualization techniques}

We have to be able to show those enormous quantities of information in a familiar, intuitive and usable form.

One of the reasons why visualisation can be so powerful has its roots in the fact that there's a series of identification and recognition operations that our brain performs in an "automatic" way without the need to focus our attention or even be conscious of them (Dürsteler [2]).

It sometimes happens that certain elements of a graphic representation, maybe a colour or an icon "pop out". We detect them instantaneously. 
These phenomena, whose visual identification is performed in a very short time lapse (typically between 200 and 250 miliseconds or less) are called pre-attentive since they occur without the intervention of consciousness. There's no need to focus on the search task. Even when they are hidden among many other objects they are identified immediately.

The goal of this common practice is providing the key ideas of this point. Since illumination is processed pre-attentively, our sight identifies the sentences in bold within a paragraph, a moving object within a set, a bigger circle within smaller ones and so on.
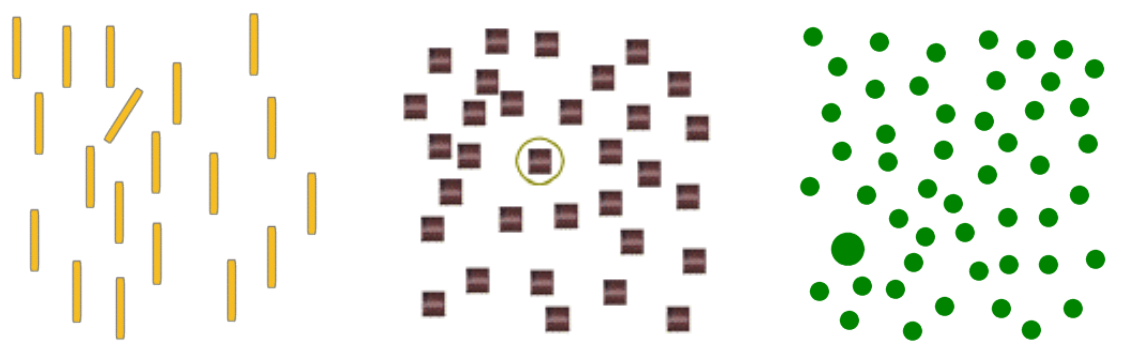

Figure 2: Some examples showing how we identify the target almost unconsciously.

\section{Pre-attentive techniques for statistics and data mining}

The development of tools for Data Mining or Information Analysis in general has it maximum value in the presentation of technology maps. They show, in 3D or in networks, enormous data arrays, standing near words with a high co-ocurrence and being far those ones with low co-ocurrence.

As we can see in Figure 3, the example shows the presentation of the authors linked with those other authors who have collaborated with them (showing the number of collaborations as well) and we can say it is very intuitive and easy to understand. It is able to find at first view, the networks and groups of inventors (Larreina and Hernando [5]).

But we can present the same graph of different manner: by highlighting what is really important with different colours and different foreground. There are more examples showing how marking or highlighting what we consider interesting for the decision-maker consumes less time in selecting the target of the analysis, as showed in Figure 4.

Other applications could be to show more information in the same image, also remarking that aspects of the analysis we consider of interest: for example, showing the nationality or the company logo in the example of the authors as showed in Figure 5.

\section{Applications}

The definition of information visualization aims three key aspects: discovery, decision making support, and explanation. Visual data mining complement 
traditional data mining and the presenting of results. Surprising patterns and decision making that appear in data sets can sometimes be found, but graphs and visual representations can provide a deeper understanding and new hypotheses.
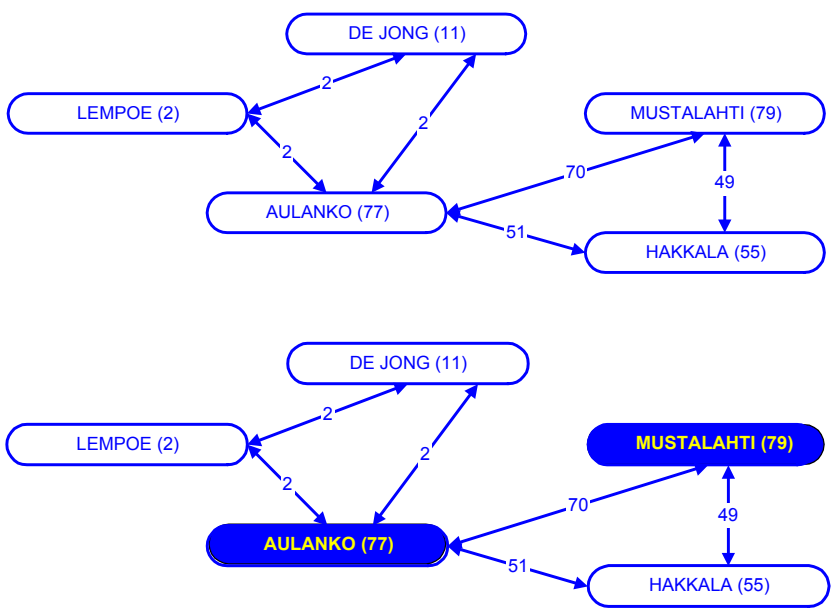

Figure 3: Network extracted from Mathéo analysing the authors of elevator patents.
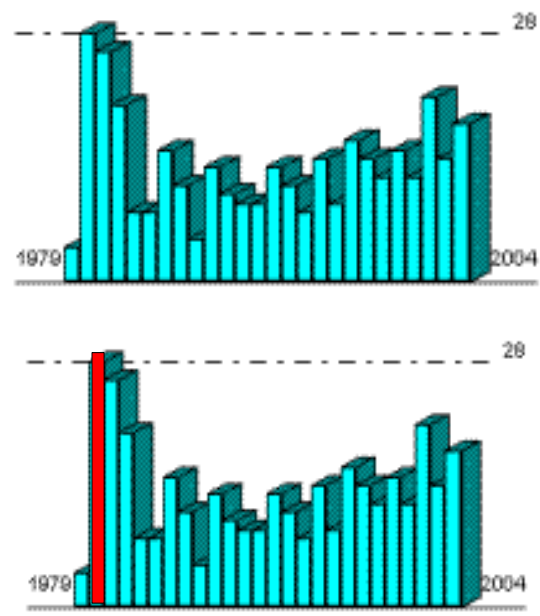

Figure 4: Histogram showing evolution in wave-energy patents. The peak in red shows the petrol-crisis.

Information visualization also serves to explain processes in ways that may lead to better predictions or to provocative insights, which can be the starting point for new actions, i.e. visualization of web traffic may explain why 
congestion occurs or why a page within a website is more frequently visited (Shneiderman [8]).

The applications of visualization techniques are large and growing as showed in Table 1.

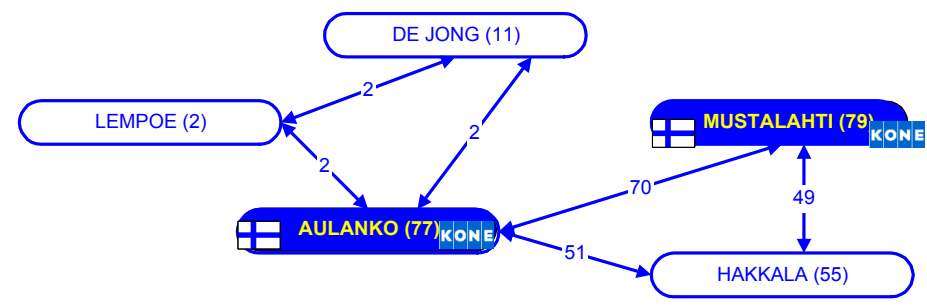

Figure 5: Relationship of authors showing the company and the nationality.

Table 1: Applications of visualization techniques.

\begin{tabular}{|c|c|}
\hline \multicolumn{2}{|c|}{ Applications of visualization techniques } \\
\hline Statistical and categorical data & $\begin{array}{l}\text { Socio-economic data, sales, import, } \\
\text { export data }\end{array}$ \\
\hline Digital Libraries & $\begin{array}{l}\text { Patents, agents, any kind of } \\
\text { publication, websites, technology } \\
\text { trends }\end{array}$ \\
\hline Personal Services & Travel, entertainment in general \\
\hline Complex documents & $\begin{array}{l}\text { Annual reports, any kind of non- } \\
\text { structured information }\end{array}$ \\
\hline Histories & Medicine, economic trends \\
\hline Classifications & Budgets, projects \\
\hline Networks & $\begin{array}{l}\text { Telecommunications, any kind of } \\
\text { people association (researchers, } \\
\text { organisations, countries) }\end{array}$ \\
\hline
\end{tabular}

\section{Conclusions}

Information visualization technology provides the information systems developer with a new set of tools in which to support the business decision maker. In this article, we introduced visualization technology as a solution for the amount of information one has to analyse in little time. We have explore also some ideas to apply to the information visualization as the use of cognitive human features. 
As creative users push the limits of current tools, designers will be pressed to provide ever greater functionality, facing some challenges: more intuition, more simple and in less space graphs to take a decision in even less time.

We have presented how taking into account some capabilities of human beings, the understanding process can be easier. The continuing shift from textual to graphical user interfaces enables people to accomplish more ambitious tasks, having access to data sets in ways that were only unthinkable just a few years ago.

The proliferation of designs indicates a lively field but many representations are poor. Evaluations by users, imagination and innovative ideas, tests within companies will all contribute to the refinement of information visualizations.

With visualization technology, new approaches to solving business problems arise. Decision-makers can fly over or swim through their data.

We wonder if these techniques would show their effectiveness. Only time will tell how these technologies impact business problem solving.

\section{References}

[1] Cruz E., Escorsa P., Guixé J., Izquierdo G., Maspons R., Ortiz I., 2003. La Vigilancia Tecnológica en el sector de los nuevos materiales. Iale Tecnologia, Cyted.

[2] Dürsteler Juan C., 2006. Processes that pop out. Infovis, the digital magazine of Infovis.net, $\mathrm{N}^{\mathrm{o}} 179$.

[3] Gilad B. and Gilad T., 1988. The business intelligence system. A new tool for Competitive Advantage. Amacom.

[4] Innovación Tecnológica, universidad y empresa. Organización de Estados americanos, 2003.

[5] Larreina S., Hernando S., 2005. Applications of technology prospective to business sectorial studies. Data Mining VI. WIT Press.

[6] Lozano Cárdenas, I.P., 2004. El análisis de patentes en el mundo de la inteligencia tecnológica competitiva. Puzzle, Revista Hispana de la Inteligencia Competitiva, $\mathrm{N}^{\circ} 8$.

[7] Pautas metodológicas en Gestión de la Tecnología y de la Innovación para Empresas. Temaguide. Fundación Cotec, 1999.

[8] Shneiderman B., Mackinlay J.D., Card, S.K., 1999. Readings in Information Visualization. Using Vision to think. Morgan Kauffman Publishers.

[9] Tegarden, David P., 1999. Business Information Visualization. Communications of the Association for Information Systems. Volume I, Paper 4.

[10] Zanassi, Brebbia, Ebecken, Melli, 2002. Data Mining III. WIT Press.

[11] Zanassi, Brebbia, Ebecken, Melli, 2005. Data Mining VI. WIT Press. 